\title{
Management of ventricular arrhythmias associated with mitral valve prolapse by combined alpha and beta blockade
}

\author{
Ghazwan S. Butrous, Milton B. Maltz, James O’Keefe, Seamus O. Banim and A. \\ John Camm
}

Department of Cardiology, St Bartholomew's Hospital, London, EC1 A 7BE, UK.

\begin{abstract}
Summary: Ventricular arrhythmias are common in patients with mitral valve prolapse. Ten patients with echocardiographically confirmed mitral valve prolapse and documented ventricular arrhythmias were included in this study. The aim was to assess the value of combined alpha- and beta-blockade (labetalol) compared with beta-blockade alone (propranolol) in the management of ventricular arrhythmias in these patients. The study was performed using physiological stress, such as the Valsalva manoeuvre, isometric exercise and treadmill exercise, to initiate ventricular arrhythmias before and after intravenous propranolol or labetalol and to document arrhythmias during 24 hour electrocardiography before and after oral medication. Labetalol and propranolol decreased the heart rate and blood pressure response to these manoeuvres to a similar extent but labetalol was more effective in the control of the ventricular arrhythmias. These findings suggest that alpha adrenergic receptors may play a role in the pathogenesis of the ventricular arrhythmias in mitral valve prolapse syndrome and that labetalol offers an alternative treatment for the management of this condition.
\end{abstract}

\section{Introduction}

Mitral valve prolapse is associated with a variety of arrhythmias (DeMaria et al., 1976; Gooch et al., 1972; Sloman et al., 1972; Winkle et al., 1975), particularly ventricular arrhythmias (Campbell et al., 1976; Savage et al., 1983). The pathogenesis of these arrhythmias is not known but may be associated with a cardiomyopathy reported in some patients with this syndrome (Mason et al., 1978), due to stretching of the papillary muscle (Cobbs \& King, 1977) or to dysautonomia (Coghlan et al., 1979). Gaffney et al. $(1979,1983)$ found that dysautonomia, manifested by decreased parasympathetic tone and increased alphabut normal beta-sympathetic responses, is commonly found in patients with mitral valve prolapse. This raises the question of whether alpha-stimulation contributes to the induction or maintenance of the ventricular arrhythmias in mitral valve prolapse patients. This hypothesis is based on the recent findings on the role of alpha-receptors in the pathogenesis of ventricular arrhythmias related to myocardial ischaemia and reperfusion and the beneficial effect of alpha-blockers in the management of these arrhythmias (Sheridan et al., 1980; Stewart et al., 1980). Although beta-blockers are useful for the

Correspondence: G.S. Butrous, M.B., Ch.B.

Accepted: 25 September 1985 treatment of ventricular arrhythmias in symptomatic patients with mitral valve prolapse (Winkle et al., 1977) they are not always successful and often other antiarrhythmic drugs may be needed (Barlow \& Pocock, 1979). In this study we assessed the use of combined alpha- and beta-blockade, in the form of labetalol (Richards et al., 1976) and compared this with propranolol in the treatment of ventricular arrhythmias occurring spontaneously and induced by physiological manoeuvres in patients with mitral valve prolapse syndrome.

\section{Patients and methods}

\section{Patients}

Ten patients (8 females) with echocardiographically (both M-mode and 2-D) confirmed mitral valve prolapse were included in the study. Their ages ranged between 24-71 (mean $48 \pm 15$ ) years. Inclusion criteria included a history of palpitations and exercise induced ventricular arrhythmias. Two patients presented with ventricular tachycardia. Ischaemic heart disease was largely excluded by persistently normal ventricular repolarization in response to formal stress testing (Bruce protocol) and no history of angina. The aims and methods of the study were fully explained to

(C) The Fellowship of Postgraduate Medicine, 1986 
Table I Valsalva manoeuvre measurements

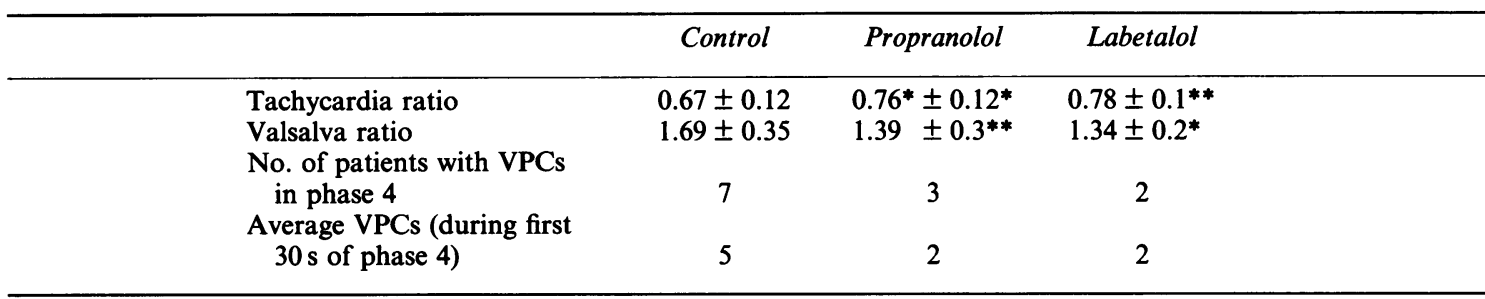

${ }^{*} P<0.01$ compared with control; ${ }^{* *} P<0.001$ compared with control.

each patient and written consent was obtained.

The protocol of the study

During real time electrocardiographic surveillance and simultaneous recording of the electrocardiogram the following tests were performed: (1) Valsalva manoeuvre at $35 \mathrm{~mm} \mathrm{Hg}$ for 15 seconds. This was repeated three times with 5 minutes rest in between each test. (2) Isometric exercise, to $30 \%$ of the patient's maximum hand grip, for 3 minutes. (3) Maximal treadmill exercise (Bruce protocol).

The above tests were performed during control (i.e. no medication) and 15-20 minutes after starting intravenous labetalol infusion $(1 \mathrm{mg} / \mathrm{kg}$ given over 10 minutes) or 15-20 minutes after intravenous infusion of propranolol $(0.2 \mathrm{mg} / \mathrm{kg}$ given over 10 minutes $)$. There was an interval of one week between the labetalol and propranolol intravenous studies when the patients took no medication.

Twenty four hour electrocardiograms were recorded using a 'Tracker' 24 hour tape recorder. The tapes were analysed by a Pathfinder analyser (Reynolds Medical, UK) to assess the frequency of ventricular premature complexes (VPC) and the pattern of these arrhythmias. After the control recording, oral labetalol $100 \mathrm{mg}$ t.d.s. was prescribed for 7 days on the last day of which the 24 hour taped electrocardiogram was repeated. After a washout period of one week a further recording was made on the 7th day of treatment with $40 \mathrm{mg}$ t.d.s. oral propranolol. The choice of drug was random and the study was of double-blind crossover design.

\section{Analysis of data}

RR intervals and blood pressures were assessed during all stages of the physiological manoeuvres mentioned above. Valsalva manoeuvre measurements, mainly tachycardia ratio (the mean $R R$ interval during phase 2 divided by the mean RR interval during control) and Valsalva ratio (the longest $R R$ interval during phase 4 divided by the mean $R R$ interval during phase 2) (Baldwa \& Ewing, 1976) were assessed. The double product of heart rate and systolic blood pressure divided by 100 was used in the assessment of the response to isometric and treadmill exercise tests. The number of VPCs was counted during all stages of these physiological manoeuvres.

The 24 hour tapes were analysed and printouts of the total VPC counts in each hour were obtained. The incidence of ventricular tachycardia ( 3 or more con $=$ secutive ventricular beats faster than 120 beats/minute) was noted.

Mean \pm standard deviation and paired Student's $t$ test were used for statistical inference.

\section{Results}

\section{Valsalva manoeuvre measurements}

Both labetalol and propranolol significantly increased the tachycardia ratio and decreased the Valsalva ratio (Table I). There were no significant differences in both ratios between labetalol and propranolol. VPCs occurred during phase 4 of the manoeuvre in seven

Table II Heart rate/blood pressure double product during isometric exercise parameters

\begin{tabular}{lrcl}
\hline & Control & Propranolol & Labetalol \\
\hline Resting & $86 \pm 17$ & $68 \pm 11^{* *}$ & $79 \pm 24$ \\
3 minute exercise & $132 \pm 27$ & $101 \pm 11^{*}$ & $97 \pm 18^{* *}$ \\
Post-exercise & $86 \pm 12$ & $71 \pm 12$ & $75 \pm 16^{*}$ \\
\hline
\end{tabular}

$P<0.01$ compared with control; ${ }^{* *} P<0.001$ compared with control. 
Table III Heart rate/blood pressure double product during treadmill exercise

\begin{tabular}{lrrr}
\hline & Control & Propranolol & Labetalol \\
\hline Resting & $95 \pm 17$ & $81 \pm 11^{*}$ & $75 \pm 14^{*}$ \\
Stage 1 & $180 \pm 40$ & $102 \pm 20^{* *}$ & $97 \pm 14^{* *}$ \\
Stage 2 & $227 \pm 47$ & $142 \pm 25^{* *}$ & $137 \pm 18^{* *}$ \\
Stage 3 & $280 \pm 90$ & $169 \pm 10^{* *}$ & $181 \pm 25^{* *}$ \\
\hline
\end{tabular}

${ }^{*} P<0.02$ compared with control; ${ }^{* *} P<0.001$ compared with control.

patients (average of five in the first 30 seconds of phase 4) during the control study. Intravenous propranolol abolished this arrhythmia in four patients and labetalol in five patients (Table I).

\section{Isometric exercise}

There was a significant reduction of the double product in response to isometric exercise after labetalol $(P<0.001)$ and after propranolol $(P<0.01)$ (Table II). There was no significant difference between the results after propranolol and after labetalol. VPCs were produced in two patients during the control study but in only one after intravenous labetalol or propranolol.

\section{Treadmill exercise}

There was a significant decrease in the double product after labetalol or propranolol (Table III). Exercise duration was not decreased by these drugs.

In nine patients an average of $36 \mathrm{VPCs} /$ minute were initiated during stage 1 and stage 2 , but in all patients the arrhythmias disappeared during stage 3 . These were abolished in four patients after propranolol and in all patients after labetalol. In the first 6 minutes after exercise an average of $24 \mathrm{VPCs} /$ minute were noticed in seven patients in the control study and in four patients after propranolol and three patients after labetalol (see Table IV).

The 24 hour electrocardiogram

There was a significant decrease in the number of
VPCs with both oral propranolol $(P<0.05)$ and labetalol $(P<0.05)$. This was most obvious in patients with initial VPC counts of more than 50/hour (Table V). In two patients with ventricular tachycardia propranolol did not suppress the arrhythmias while labetalol did. These two patients were followed up for 2 and 3 years on labetalol with no recurrence. In one patient, subsequent withdrawal of labetalol led to reappearance of ventricular tachycardia.

\section{Discussion}

There is considerable variation in the definition of mitral valve prolapse syndrome. The original clinical description, based on the auscultatory findings of an apical late systolic murmur and non-ejection systolic click (Barlow et al., 1963) is heavily relied on. Recently M-mode and 2-D echocardiography have been used to diagnose mitral valve prolapse. These techniques have improved the diagnostic accuracy in this condition as demonstrated by the Framingham study in which many subjects who had echocardiographic evidence of mitral valve prolapse had no specific auscultatory findings (Savage et al., 1983). In this study only patients with clinically suspected mitral valve prolapse which was subsequently confirmed by both M-mode and 2-D echocardiography were included. The patients also complained of palpitations and had documented evidence of ventricular arrhythmias. These specific selection criteria were adopted in order to test the relevance of increased alpha activity as proposed by Gaffney and his coworkers $(1979,1983)$ to the ventricular arrhythmias occurring in this syn-

Table IV Ventricular arrhythmias during and after treadmill exercise

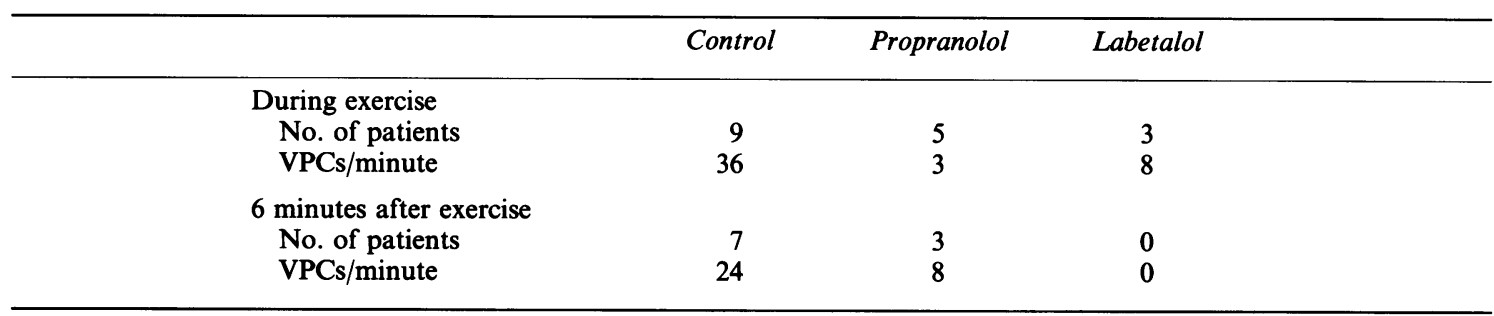


Table V The average number of ventricular premature beats/hour during 24 hour electrocardiographic recording

\begin{tabular}{rlll}
\hline Patient no. & Control & Propranolol & Labetalol \\
\hline 1 & 653 & 198 & 113 \\
2 & 685 & 105 & 39 \\
3 & 700 & $*$ & 10 \\
4 & 10 & 10 & 1 \\
5 & 181 & 1 & 4 \\
6 & 16 & 17 & 10 \\
7 & 139 & 11 & 8 \\
8 & 6 & 3 & 450 \\
9 & 81 & 43 & 20 \\
\hline
\end{tabular}

* Oral propranolol or labetalol could not be prescribed because of a history of severe bradycardia.

drome. Labetalol which has combined alpha- and beta-blocking action was chosen because beta-blockers, in particular propranolol, have previously been shown to be effective in decreasing the number of ventricular ectopic beats in these patients (Winkle et al., 1977). This favourable effect of beta-blockers has not been consistent, in particular with arrhythmias refractory to other antiarrhythmic agents (Barlow \& Pocock, 1979).

In this study we employed physiological manoeuvres such as the Valsalva manoeuvre, isometric exercise and treadmill exercise to induce ventricular arrhythmias. Autonomic tone imbalance is well known to induce arrhythmias in a variety of conditions (Zipes et al., 1983) and ventricular arrhythmias are usually associated with exercise in mitral valve prolapse (Pocock \& Barlow, 1970). In this group of patients VPCs were initiated in three situations: (a) during the first two stages of treadmill exercise, where there is a withdrawal of parasympathetic tone and gradual increase in the sympathetic tone; (b) within the first 6 minutes after exercise, when there is a gradual increase in parasympathetic tone and decrease in sympathetic activity and (c) during phase 4 of the Valsalva manoeuvre when there is a rapid increase in parasympathetic activity preceded by sympathetic predominance (phase 2). These observations suggest that fluctuations of autonomic balance may provoke these arrhythmias.

\section{References}

BALDWA, V.S. \& EWING, D.J. (1976). Heart rate response to Valsalva manoeuvre. British Heart Journal, 39, 641.

BARLOW, J.B., POCOCK, W.A., MARCHAND, P. \& DENNY, M. (1963). The significance of late systolic murmurs. American Heart Journal, 66, 443.

BARLOW, J.B \& POCOCK, W.A. (1979). Mitral valve prolapse: the specific billowing mitral leaflet syndrome or an insig-
The role of alpha-receptors on the electrophysiology of the heart is still not clear. There is an increase in alpha responses in mitral valve prolapse patients (Gaffney et al., 1979) and this may play a similar role in the genesis of ventricular arrhythmias as does the increased alpha-activity associated with acute ischaemia or reperfusion (Corr et al., 1981).

Both propranolol and labetalol significantly decreased the incidence of arrhythmias in this group of patients; labetalol appeared to be more effective. Whether this is due to additional alpha effect could not 8 be established from this study. Antiarrhythmic effects of labetalol (Mazzola et al., 1981) may be due to betato blockade, alpha-blockade or membrane stabilization (Dukes \& Vaughan Williams, 1984). Labetalol changed Valsalva manoeuvre, isometric and treadmill exercise measurements similarly to propranolol, suggesting that both drugs produced a similar degree of beta-blockade.

Patients with mitral valve prolapse who have asymptomatic VPCs and no inducible ventricular tachycardia during electrophysiological study may have a benign prognosis without treatment (Morady et al., 1984). Life threatening arrhythmias, however, have been reported and may cause sudden death (Jeresaty, 1976). We have shown that labetalol may be a suitable alternative to isolated beta-blockade which is worth considering in the management of this condition.

nificant non-systolic clock. American Heart Journal, 97, 277.

CAMPBELL, R.W.F., GODMAN, M.G., FIDDLER, G.I. \& MARQUIS, R.M. (1976). Ventricular arrhythmias in the syndrome of balloon deformity of mitral valve. Definition of possible high risk group. British Heart Journal, 38, 1073. COBBS, B.W. \& KING, S.B. (1977). Ventricular buckling: a 
factor in the abnormal ventriculogram and peculiar hemodynamics associated with mitral valve prolapse. American Heart Journal, 93, 741

COGHLAN, H.C., PHARES, P., COWLEY, M., COPLEY, D. \& JAMES, T.N. (1979). Dysautonomia in mitral valve prolapse. American Journal of Medicine, 67, 236.

CORR, P.B., SHAYMAN, J.A., KRAMER, J.B. \& KIPNIS, R.J. (1981). Increased alpha-adrenergic receptors in ischaemic cat myocardium. A potential mediator of electrophysiological derangements. Journal of Clinical Investigation, 67, 1232.

DEMARIA, A.N., AMSTERDAM, F.A., VISMARA, L.A., NEWMANN, A. \& MASON, D.T. (1976). Arrhythmias in the mitral valve prolapse syndrome. Annals of Internal Medicine, 84, 656.

DUKES, I.D. \& VAUGHAN WILLIAMS, E.M. (1984). Electrophysiological effects of alpha-adrenoceptor antagonists in rabbit sino-atrial node, cardiac Purkinje cells and papillary muscles. British Journal of Pharmacology, 83, 419.

GAFFNEY, F.A., KARLSSON, E.S., CAMPBELL, W., SCHUTTE, J.E., NIXON, J.V., WILERSON, J.T. \& BLOMQVIST, C.G. (1979). Autonomic dysfunction in women with mitral valve prolapse syndrome. Circulation, 59, 894.,

GAFFNEY, F.A., BASTIAN, B.C., LANE, L.B., TAYLOR, W.F., HORTON, J., SCHUTTE, J.E., GRAHAM, R.M., PETTINGER, W., BLOMQVIST, C.G. \& MOORE, W.E. (1983). Abnormal cardiovascular regulation in the mitral valve prolapse syndrome. American Journal of Cardiology, 52, 316.

GOOCH, A.S., VICENCIO, F., MARANHAD, V. \& GOLDBERG, H. (1972). Arrhythmias and left ventricular asynergy in the prolapsing mitral valve leaflet syndrome. American Journal of Cardiology, 29, 611.

JERESATY, R.M. (1979). Sudden death in the mitral valve prolapse-click syndrome. American Journal of Cardiology, 37, 317.

MASON, J.W., KOCH, F.H., BILLINGHAM, M.E. \& WINKLE, R.A. (1978). Cardiac biopsy evidence for a cardiomyopathy associated with symptomatic mitral valve prolapse. American Journal of Cardiology, 42, 557.

MAZZOLA, C., FERRARIO, N., CALZAVARA, M.P., GUFFANTI, E. \& VACCARELLA, A. (1981). Acute antihypertensive and antiarrhythmic effects of labetalol. Current Therapeutic Research, 29, 613.
MORADY, F., SHEN, E., BHANDARI, A., SCHWARTZ, A. \& SCHEINMAN, M.M. (1984). Programmed ventricular stimulation in mitral valve prolapse: analysis of 36 patients. American Journal of Cardiology, 53, 135.

POCOCK, W.A. \& BARLOW, J.B. (1970). Postexercise arrhythmias in the billowing posterior mitral leaflet syndrome. American Heart Journal, 80, 740.

RICHARDS, D.A., TUCKMAN, J. \& PRICHARD, B.N.C. (1976). Assessment of alpha and beta adrenoceptors blocking actions of labetalol. British Journal of Clinical Pharmacology, 3, 849.

SAVAGE, D.D., DEVEREUX, R.B., GARRISON, R.J., CASTELLI, W.P., ANDERSON, S.J., LEVY, D., THOMAS, H.E., KANNEL, W.B. \& FEINLEIB, M. (1983). Mitral valve prolapse in the general population. 2. Clinical features: The Framingham study. American Heart Journal, $106,577$.

SHERIDAN, D.J. \& PENKOSKE, P.A., SOBEL, B.E. \& CORR, P.B. (1980). Alpha adrenergic contribution to dysrhythmia during myocardial ischaemia and reperfusion in cats. Journal of Clinical Investigation, 65, 161.

SLOMAN, G., WONG, M.A. \& WALKER, J. (1972). Arrhythmias on exercise in patients with abnormalities of the posterior leaflet of the mitral valve. American Heart Journal, 83, 312.

STEWART, J.R., BURMEISTER, W.E., BURMEISTER, J. \& LUCCHESI, B.R. (1980). Electrophysiological and antiarrhythmic effects of phentolamine in experimental coronary artery occlusion and reperfusion in the dog. Journal of Cardiovascular Pharmacology, 2, 77.

WINKLE, R.A., LOPES, M.G., FITZGERALD, J.W., GOODMAN, D.J., SCHROEDER, J.S. \& HARRISON, D.C. (1975). Arrhythmias in patients with mitral valve prolapse. Circulation, 52, 73.

WINKLE, R.A., LOPES, M.G., GOODMAN, D.J., FITZGERALD, J.W., SCHROEDER, J.S. \& HARRISON, D.C. (1977). Propranolol for patients with mitral valve prolapse. American Heart Journal, 93, 422.

ZIPES, D.P., MARTINS, J.B., RUFFY, R., PRYSTOWSKY, E.N. \& GILMOUR, R.F. (1983). Role of the autonomic nervous system in the genesis of ventricular arrhythmias. In Frontiers of Cardiac Electrophysiology. Rosenbaum, M.B. and Elizarti, M.V. (ed.) pp.522-551. Martinus Nijhoff Publishers: Boston. 